\title{
Simulation of Fuzzy Logic Based Shunt Hybrid Active Filter for Power Quality Improvement
}

\author{
Sakshi Bangia \\ Department of Electrical Engineering, YMCAUST Faridabad, India \\ Email: sakshibangia@gmail.com
}

P R Sharma

Chairman, Department of Electrical Engineering, YMCAUST Faridabad, India

Email: prsharma1966@gmail.com

Maneesha Garg

Department Humanities and Applied Science, YMCAUST Faridabad, India

Email: garg_maneesha@yahoo.com

\begin{abstract}
This paper deals with the implementation of fuzzy logic based Shunt Hybrid Active Filter (SHAF) with non-linear load to minimize the source current harmonics and provide reactive power compensation. Comparison with Proportional Integral (PI) based SHAF is also analyzed. Shunt Hybrid Active Filter is constituted by Active Filter connected in shunt and shunt connected three phase single tuned LC filter for $5^{\text {th }}$ harmonic frequency with rectifier load. The Active Filtering System is based on Synchronous Reference Frame. The proposed fuzzy logic based control strategy improves active filter operation and reduces the selective harmonic contents. The control strategies are demonstrated through MATLAB Simulated Environment.
\end{abstract}

Index Terms - Hybrid Active Filter, Total Harmonic Reduction, Power Quality, Fuzzy Logic Control

\section{Introduction}

The design ramification and immense cost of losses of the conventional passive filters, as well as their restricted potential to minimize inter-harmonics and non-characteristic harmonics, has encouraged the advancement of harmonic compensation by means of power electronic devices commonly referred to as Active Power Filters. The Active Power Filter (APF) is implemented using self-supported dc bus with three phase Voltage Source Inverter(VSI).The operating principle of APFs is primarily canceling the distorting harmonic current by analyzing them and generating a harmonic current spectrum in phase opposition to the measured current.

Passive filters were traditionally preferred because of low cost and simple robust structure as they used to absorb harmonic currents. But they offer fixed compensation and generate system resonance [1]-[5]. The shunt active filters can provide compensation of harmonics, reactive power and/or neutral current in ac networks, regulation of terminal voltage, suppression of the voltage flicker, and improve voltage balance in three-phase system [6], [7], [8]. Then next topology shunt hybrid power filter named transformerless hybrid filter was proposed which uses a single LC passive filter for each phase and a small rated voltage source converter based active power filter [9]

The hybrid filter consists of a three-phase LC filter tuned at the 5th harmonic frequency and a small-rated three-phase voltage-source inverter. The compensating current of the hybrid shunt active filter consists of a fundamental component and harmonic components and they are determined by the impedance of the LC filter and are controlled by the active filter.

The paper is organized as follows.In section II Design of shunt hybrid Active Filters are explained .The details of the control scheme used is explained in section III. Section IV outlines the MATLAB implementation and simulation results for the proposed configuration. Finally conclusion is presented in Section $\mathrm{V}$

\section{Design of Shunt Hybrid Active Filters}

Fig 1 shows the proposed shunt hybrid active filters with nonlinear load drawing non-sinusoidal current. The system consists of active filter in shunt with passive filter. The shunt hybrid active filter works such that ac mains current is created to have only fundamental frequency component, by absorbing harmonics all the way through passive filters. The active filter performs as a harmonic voltage source, compensates voltage drop in passive filter at harmonic frequencies at PCC, 


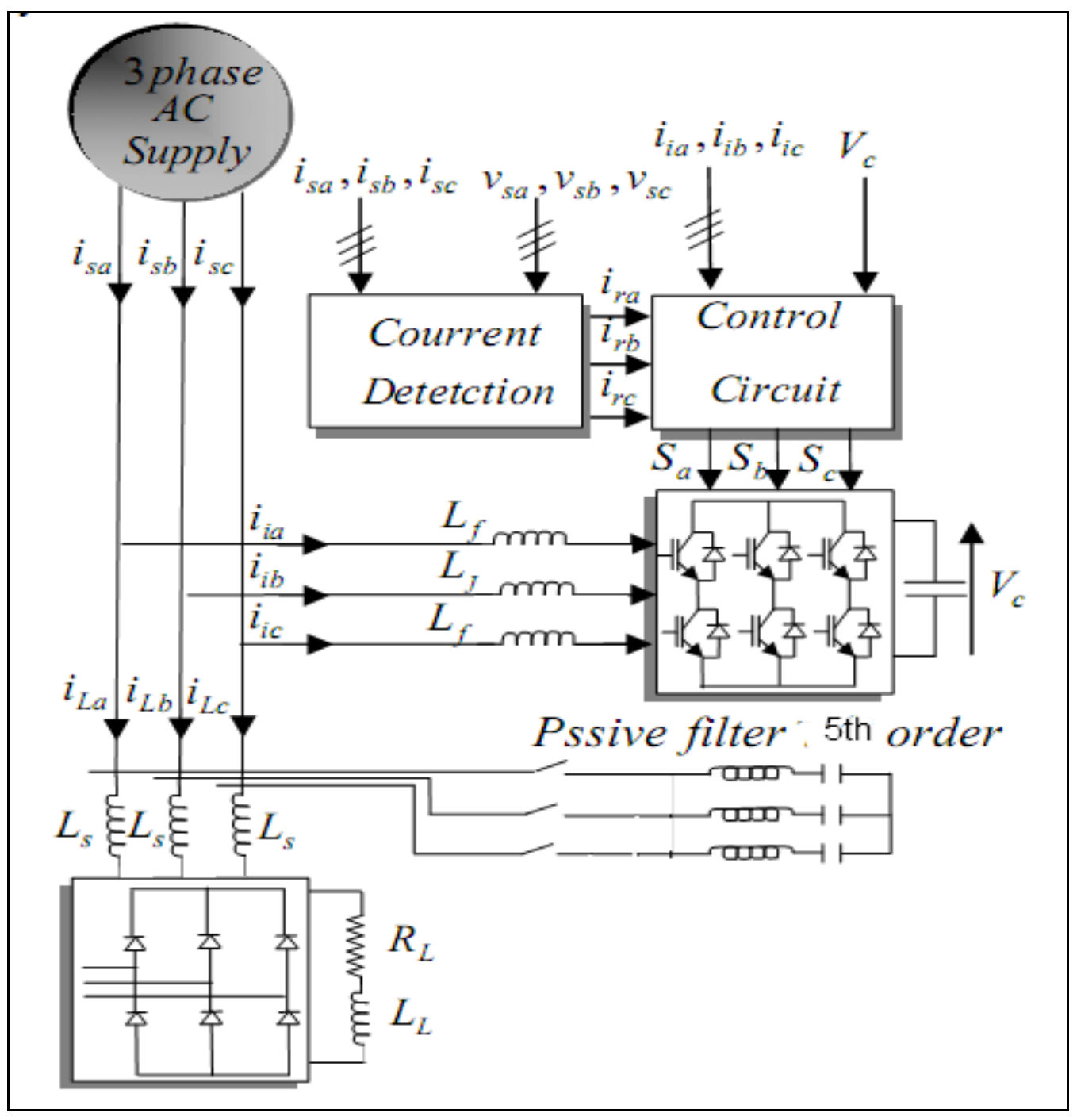

Fig. 1: Circuit Diagram for Shunt Hybrid Active Filter

The fundamental shunt passive filtering law is to catch the selective harmonic currents in LC circuits, tuned up to the harmonic filtering frequency to be eliminated from power system. In single-tuned filter, the reactance of inductor is equal to that of capacitor at resonant frequency ' $f$ '.

$$
f=\frac{1}{2 \pi \sqrt{L_{f} C_{f}}}
$$

The primary step to design a single tuned filter is to first define the size of the capacitor with a reasonable power factor at the operating line voltage.

$$
X_{c}=\frac{V_{L-L}^{2}}{k V A R \cdot \text { filter }}
$$

Once the size of the capacitor is defined with a realistic power factor at the operating line voltage, the reactance value can be calculated by using (2) where filter kVAR signifies the reactive power capacity of the filter and $V_{L-L}$ stands for the line to line rated voltage of the filter. Other parameter included in filter design is resistance value of filter $\mathrm{R}$ which can be determined by defining the sharpness of filter $Q$, also termed as Quality factor.

$$
Q=\frac{\sqrt{L_{f}} C_{f}}{R}
$$

\section{Control Scheme}

In Voltage Source Converter type Active Power Filter the circuit has Dc link capacitor and no additional DC supply is required for DC link side; because a small amount of current at fundamental frequency is drained from the supply to meet the filter losses so that DC link 
voltage is kept stable. Thus Synchronous Reference Frame Theory was introduced in [11] is used to generate the pulses for the semiconductor switches which support the maximum filter current introduced to the main side. The three phase currents $\left(i_{a}, i_{b}, i_{c}\right)$, load currents $\left(\mathrm{i}_{\mathrm{La}}, \mathrm{i}_{\mathrm{Lb}}, \mathrm{i}_{\mathrm{Lc}}\right)$, the PCC voltages $\left(\mathrm{v}_{\mathrm{sa}}, \mathrm{v}_{\mathrm{sb}}, \mathrm{v}_{\mathrm{sc}}\right)$ and $\mathrm{dc}$ bus voltage $\left(\mathrm{v}_{\mathrm{dc}}\right)$ of active filter are sensed as feedback signals. Load currents are transformed into synchronously rotating reference frame $\mathrm{d}$ axis and $\mathrm{q}$ axis by using $\cos \theta$ and $\sin \theta$ where $\theta$ is derived from three phase PLL circuit.
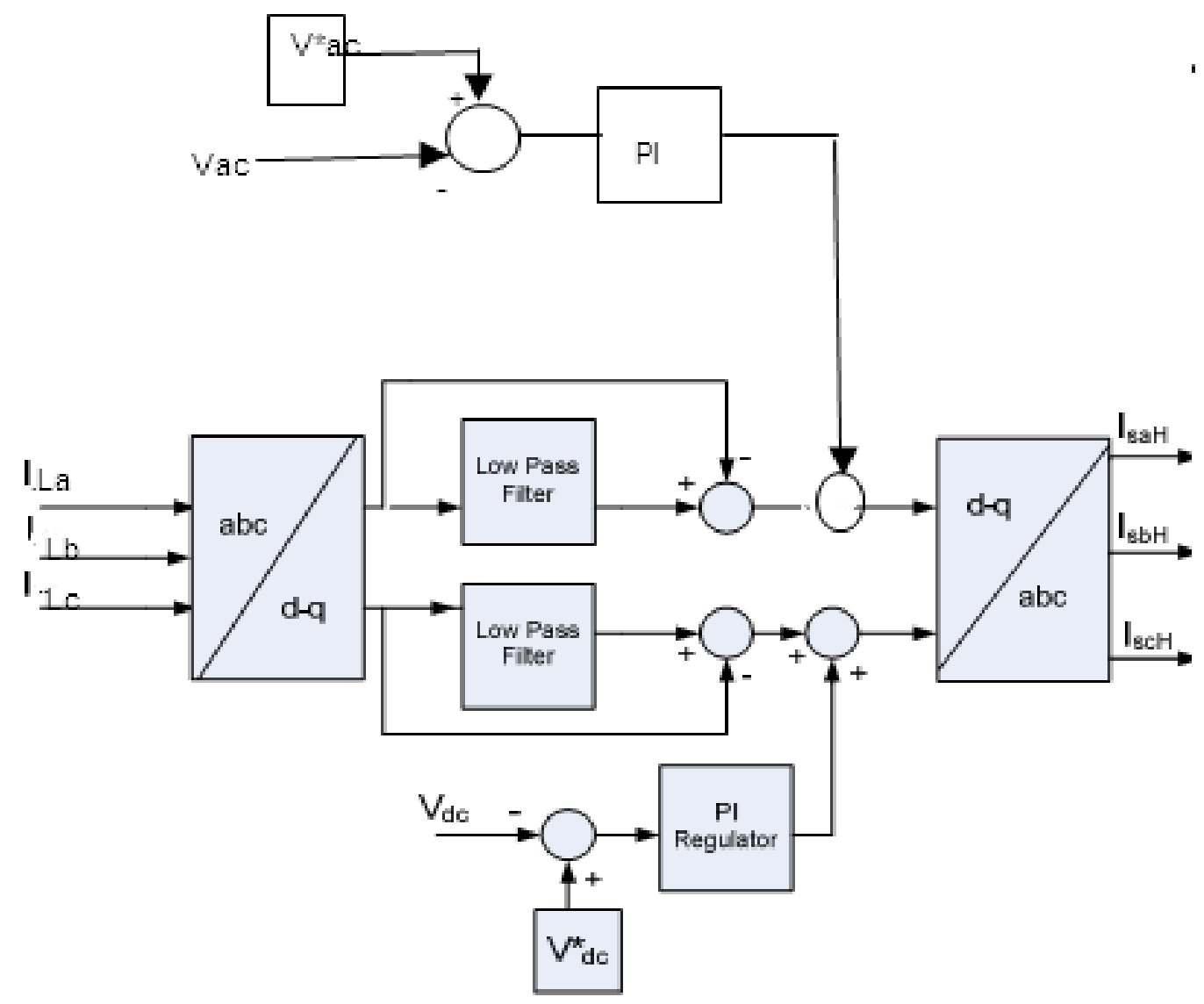

Fig. 2: Synchronous Reference Frame Method

The d-axis and q-axis currents consist of fundamental and harmonic components as

$$
\begin{aligned}
& \boldsymbol{i}_{L d}=\boldsymbol{i}_{d d}+\boldsymbol{i}_{d a} \\
& \boldsymbol{i}_{L q}=\boldsymbol{i}_{q d}+\boldsymbol{i}_{q a}
\end{aligned}
$$

\subsection{PI Controller}

The PI controller consists of proportional term and integral term. Proportional value determines the reaction to the current error; the Integral determines the reaction based on the sum of recent errors. The reference currents for the control of active filter are generated according to the equation (6). The output of PI controller at the dc bus voltage of active filter is considered as the current $\left(\mathrm{i}_{\text {loss }}\right)$ for meeting its losses.

$$
i_{\text {loss }(n)}=i_{\text {loss }(n-1)}+k_{p d}\left(v_{d e(n)}-v_{d e(n-1)}\right)+k_{i d} v_{d e(n)}
$$

where, $v_{d e}-v_{d e(n-1)}$ is the error between the reference $\left(\mathrm{v}_{\mathrm{dc}} *\right)$ and sensed $\left(\mathrm{v}_{\mathrm{dc}}\right)$ dc voltage at the $n$th sampling instant. $\mathrm{K}_{\mathrm{pd}}$ and $\mathrm{K}_{\mathrm{id}}$ are the proportional and the integral gains of the $\mathrm{dc}$ bus voltage PI controller.

The reference source current is therefore expressed as,

$$
i_{d}^{*}=i_{d d}+i_{\text {loss }}
$$

Similarly PI controller is used to regulate reactive power

$$
i_{q r(n)}=i_{q r s(n-1)}+k_{p q}\left(v_{t e(n)}-v_{t e(n-1)}\right)+k_{i q} \boldsymbol{v}_{t e(n)}
$$

The reference supply quadrature axis current is as

$$
i_{q}^{*}=i_{q d}+i_{q r}
$$


where, $\boldsymbol{V}_{t e(n)}=\mathcal{V}_{s}^{*}-\boldsymbol{V}_{(n)}$ denotes the error between reference $\left(\mathrm{v}_{\mathrm{s}}^{*}\right)$ and $\operatorname{actual}\left(\mathrm{v}_{\mathrm{s}(\mathrm{n})}\right)$ terminal voltage amplitudes at the $n$ sampling instant. $\mathrm{K}_{\mathrm{pq}}$ and $\mathrm{K}_{\mathrm{iq}}$ are the proportional and the integral gains of the PI controller.

\subsection{Fuzzy Logic Controller}

Conventionally PI controllers have been used to maintain the DC bus voltage. In this paper, the followed control strategy employs the decision making for the control of DC bus by using Fuzzy Logic controller. The concept of Fuzzy Log ic Controller (FLC) was offered in 1965 by Professor Lotfi Zadeh .He proposed a way of processing data by consenting partial set membership rather than crisp set me mbership [12]. Thereafter, it was recognized to be an admirable choice for many control systemapplications as it mimics human control logic.

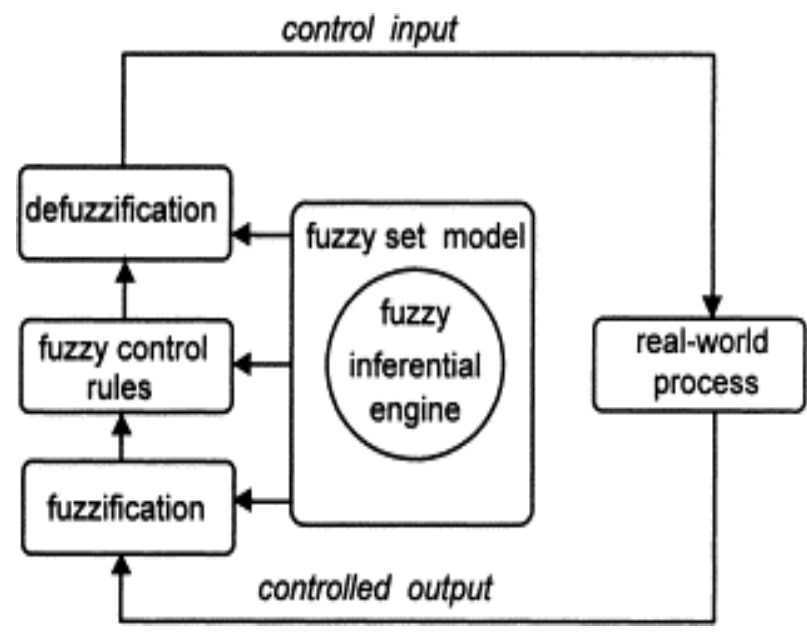

Fig. 3: Architecture of Fuzzy Logic Controller



Fig 4 input/output variables and fuzzy control rules

Fig 3 shows the architecture of Fuzzy Logic Controller (FLC).The internal structure of Fuzzy controller consis ts of fuzzification, dec ision making unit, rule base, defuzzification,. The triangular shaped membership functions are considered for the input variables error ' $\mathrm{e}$ ' $\left(\mathrm{v}^{*}{ }_{\mathrm{dc}}-\mathrm{v}_{\mathrm{dc}}\right)$, change in error 'ce' $(\mathrm{de} / \mathrm{dt})$ and output 'du' as shown in Figs 4.Three membership functions namely SN (s mall negative),S (s mall), SP (small positive), ZE (zero), are selected for input variables and PS (positive small), NS (negative s mall) and $\mathrm{Z}$ (zero) are chosen for output variables .Firstly all three variables are normalized with in the membership function range. In the second stage, the fuzzy variables are processed by an interface which executes 9 control rules as shown in Fig 3. In third stage as defuzzification and denormalization, the fuzzy variables are converted back to crisp variables. Fig 4 shows the shapes of input/output variables and the assignment of fuzzy control rules. The peak value of reference currents is estimated by regulating the DC link voltage using fuzzy logic controller. The error and change in error are considered as the input variables and current $\operatorname{loss}\left(\boldsymbol{i}_{\text {loss }}\right)$ as output variable.

\subsection{Hystersis Controller}

There are several current control strategies proposed in the literature [13], namely, PI control, Average Current Mode Control (ACMC), Sliding Mode Control (SMC) and hysteresis control. Among the various current control techniques, hysteresis control is the most popular one for active power filter applications. The 
fundamental of hysteres is current control says that it is basically an on-line PWM control that fixes the output voltage of the inverter instantaneously. The switching frequency can be changed by the width of the hysteres is band $h_{b}$. The upper device and the lower device in one phase leg of VSI are switched in complementary manner. If upper switch is OFF and lower switch is ON in the phase "a" leg then 0. If upper switch is ON and lower switch is OFF in the phase "a" leg then 1.Similarily switching of devices can be done for phase "b" and phase "c"

\section{Matlab Based Simulation}

The proposed fuzzy logic based shunt hybrid active filter is developed in MATLAB using Power System
Block set Toolbox as shown in Fig 1. Three-phase source is supplied by a sinusoidal balanced three-phase $415 \mathrm{~V}$ source and $50 \mathrm{~Hz}$ frequency with a source inductance of $2 \mathrm{mH}$ and a source resistance of $0.2 \Omega$. The active filter consists of an IGBT three-leg bridge. One $2200 \mu \mathrm{F}$ capacitors is connected at the dc side. The reference voltage at the capacitors is $750 \mathrm{~V}$. A s mallrated filter has been included to minimize the switching ripples at the inverter output. The load used in simulating the system are three phase unbalance nonlinear load. The component values for the passive filter network and other parameters of the system are given in Table 1.Passive filter arrangement provides $50 \%$ Reactive VAR compensation at the fundamental frequency

Table 1: parameters of the system

\begin{tabular}{|l|l|}
\hline Parameters & \multicolumn{1}{c|}{ Values } \\
\hline Supply voltage & $415 \mathrm{~V}(\mathrm{~L}-\mathrm{L}), 50 \mathrm{~Hz}$ \\
\hline Loads: & $\begin{array}{c}\text { (i) Linear: phase } \mathrm{a}=25 \Omega \\
\text { Phase } \mathrm{b}=10 \Omega \text { and } 80 \mathrm{mH} \\
\text { Phase } \mathrm{c}=10 \Omega \text { and } 80 \mathrm{mH}\end{array}$ \\
& (ii) Nonlinear: Three phase full bridge, rectifier drawing $5 \mathrm{~A}$ \\
\hline Shunt Active Filter: Interfacing Inductance & $\mathrm{L}_{\mathrm{f}}=5.5 \mathrm{mH}, \mathrm{R}_{\mathrm{f}}=0.25 \Omega$ \\
\hline DC bus capacitance & $22000 \mathrm{e}-6 \mathrm{~F}$. \\
\hline Referenced Dc voltage & $750 \mathrm{~V}$ \\
\hline Tuned Passive Filter & $\mathrm{C}_{5}=129.4 \mathrm{e}-6 \mathrm{~F} ; \mathrm{L}_{5}=3.1 \mathrm{mH}$ \\
\hline
\end{tabular}

\section{Comparis on between Different Types of Configurations}

The performance of the proposed scheme is evaluated for its application to unbalanced non-linear load for different configurations of filters viz passive filters, pure shunt active filter, shunt hybrid active filter, fuzzy based shunt hybrid filter. In the present study the 5th tuned branches of passive filter are considered. Resonance problem occurs at fifth harmonic frequency when passive filter operates alone. The hybrid filter produces the resonance caused by capacitors in the passive filters with source side inductive impedance and amplification phenomenon at fifth harmonic frequency disappears However when the proposed fuzzy based shunt hybrid active filter is curved with Synchronous Reference Frame method, the most dominant harmonics of the load are greatly reduced. Total Harmonic Distortion is reduced from $14.74 \%$ to $2.34 \%$

Table 2 shows the THD for all three phases for different types of filter. It can be seen from Fig 5 and Table III that proposed hybrid filter system is able to reduce the $5^{\text {th }}$ harmonic of supply current to $1.47 \%$ whereas PI based shunt hybrid filter system reduce the 5th harmonic of supply current to $1.68 \%$.The THD of the ac supply current reduces to $4.53 \%$ with passive filters alone as the major component of the load current without any filter is composed of $5^{\text {th }}$ harmonic.

Table 2: THD for different phases (in percentage)

\begin{tabular}{|c|c|c|c|c|}
\hline Phase & $\rightarrow$ & \multirow{2}{*}{ Phase a } & \multirow{2}{*}{ Phase b } & \multirow{2}{*}{ Phase } \\
\hline Type of filter & $\downarrow$ & & & \\
\hline Load current without filter & & 14.74 & 16.27 & 19.66 \\
\hline Pure shunt active filter & & 3.27 & 4.58 & 3.75 \\
\hline PI based hybrid filter & & 2.65 & 3.15 & 2.64 \\
\hline Fuzzy based shunt hybrid filter & & 2.34 & 2.64 & 2.27 \\
\hline
\end{tabular}

Figure 5(a) shows the waveform of the load current and figure 5(b), 5(c) and 5(d) shows the source current by using pure shunt active filter, shunt hybrid active filter and fuzzy based shunt hybrid active filter. 




Fig. 5(a): waveform of the load current

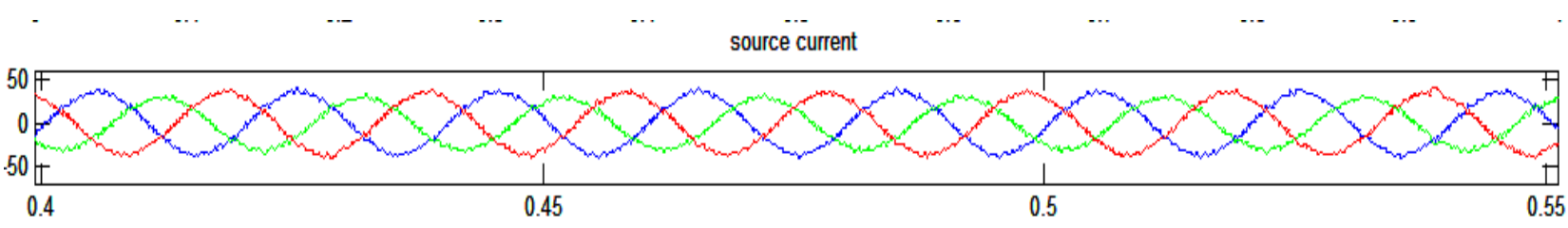

Fig. 5(b): waveform of the source current using pure shunt active filter

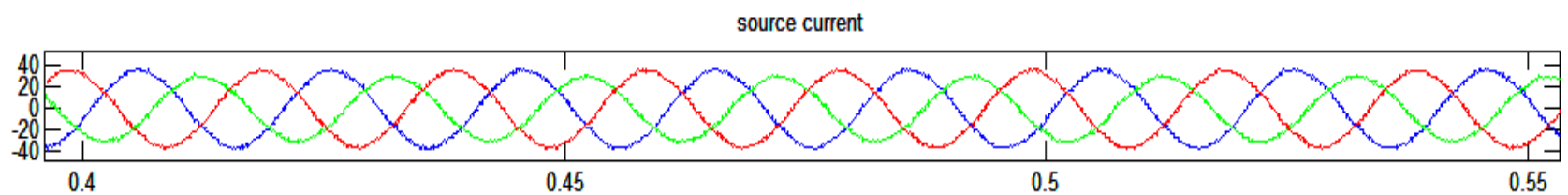

Fig. 5(c): waveform of the source current using shunt hybrid active filter



Fig. 5(d): waveform of the source current using fuzzy based shunt hybrid active filter


Fig. 6: Source Voltage, Source Current Load Voltage, Load Current, Capacitor Voltage And Filter Current Using Fuzzy Based Shunt Hybrid Active Filter 
Fig.6 shows source voltage, source current load voltage, load current ,capacitor voltage and filter current using fuzzy based shunt hybrid active filter respectively. The values of harmonic content of load current and supply current from simu lation in percent of fundamental current using different filter configurations have been given in the Table 3

Table 3: harmonic content of load current and supply current of simulation result in percent of fundamental current

\begin{tabular}{|l|c|c|c|c|c|c|}
\hline & $5^{\text {th }}$ & $7^{\text {th }}$ & $11^{\text {th }}$ & $13^{\text {th }}$ & $17^{\text {th }}$ & $19^{\text {th }}$ \\
\hline Load current Without Filter & 12.76 & 5.42 & 3.92 & 2.23 & 1.55 & 0.97 \\
\hline Source current with Passive Filter & 0.20 & 2.69 & 2.57 & 1.64 & 1.31 & 0.89 \\
\hline $\begin{array}{l}\text { Source current with Pure Shunt Active } \\
\text { Filter }\end{array}$ & 1.83 & 0.54 & 0.60 & 0.65 & 0.83 & 0.05 \\
\hline $\begin{array}{l}\text { Source current with Shunt Hybrid Active } \\
\text { Filter }\end{array}$ & 1.68 & 1.03 & 0.23 & 0.21 & 0.19 & 0.13 \\
\hline $\begin{array}{l}\text { Source current with Fuzzy based Shunt } \\
\text { Hybrid Active Filter }\end{array}$ & 1.47 & 0.80 & 0.27 & 0.15 & 0.39 & 0.27 \\
\hline
\end{tabular}

Fig 7 shows comparison of harmonic content of load current by shunt hybrid active filter using PI controller and fuzzy based shunt hybrid active filter.It can be clearly analysed that using decision making power of fuzzy controller $5^{\text {th }}$ harmonic contents are considerably reduced from $12.76 \%$ (without any filter) to $1.47 \%$ by using fuzzy based hybrid filter.



Fig. 7: Comparison graph for PI based and Fuzzy based shunt hybrid active filter

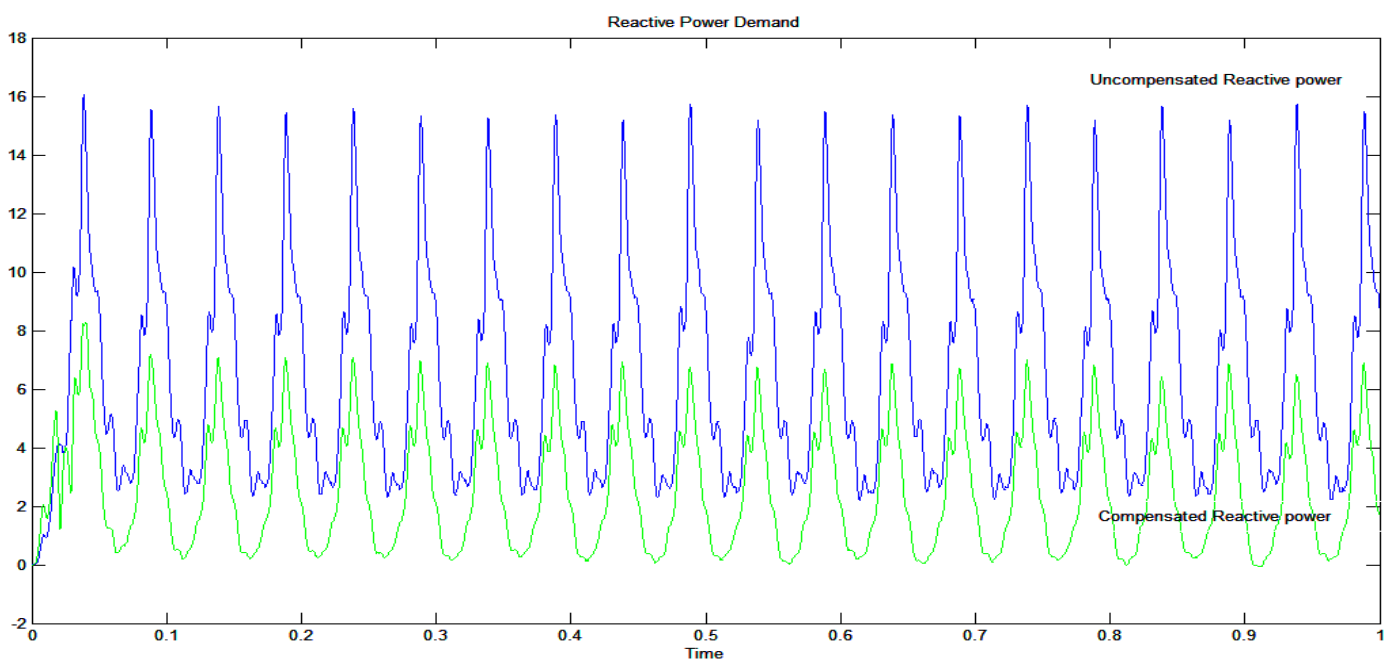

Fig. 8: Reactive Power for uncompensated and compensated system 
Fig 8 shows uncompensated and compensated reactive power compensations and it can be analysed that passive filter parameters are calculated at 50\% reactive power demand at fundamental frequency.

\section{Conclusion}

The simulated fuzzy logic based shunt active hybrid active filter proves remarkable filtering results. The proposed control strategy has demonstrated the capability of intelligent controller for hybrid power filter to minimize the overall THD and the selective harmonic content of the source current. A complete evaluation between a conventional PI based hybrid active power filter and, fuzzy based the hybrid power filter is presented. Thus FLC seems more suitable and flexible for the active filter since it does not need a complex mathematic model to tune the PI controller gains and it is more robust compared to PID.

\section{References}

[1] M. Rastogi, N. Mohan, and A.-A. Edris, "Hybridactive filtering of harmonic currents in power systems," IEEE Trans. Power Delivery, vol. 10,no. 4, pp. 1994-2000, Oct. 1995.

[2] H. Fujita and H.A kagi, "A practical approach to harmonic compensation in power system-series connection of passive, active filters," IEEE Trans. Ind. Applicat., vol. 27, no. 6, pp. 1020-1025, Nov./Dec. 1991.

[3] H. Fujita and H.Akagi, "A new power line conditioner for harmonic compensation in power systems," IEEE Trans. Power Delivery, vol. 10, no. 3, pp.1570-1575, Jul. 1994.

[4] H. Fujita and H.Akagi, "A hybrid active filter for damping of harmonic resonance in industrial power system," IEEE Trans. Power Electron., vol. 15, no. 2, pp. 215-222, Mar. 2000.

[5] S. Bhattacharya, P.-T. Cheng, and D. M. Divan, "Hybrid solutions for improving passive filter performance in high power applications," IEEE Trans. Ind. Application, vol. 33, no. 3, pp. 732-747, May/Jun. 1997.

[6] H. Akagi, "New trends in active filters for power conditioning," IEEE Trans. Ind. Application., vol. 32, no. 6, pp. 1312-1320, Nov./Dec. 1996.545-557, Apr. 1998.

[7] K. Al-Haddad, A. Chandra, B. Singh, and B. N. Singh, "An improved control algorithm of shunt active filter for voltage regulation, harmonic elimination, power-factor correction, and balancing of nonlinear loads," IEEE Trans. Power Electron., vol. 15, no. 3, pp. 495-507, May 2000.
[8] L. Gyugyi and E. C. Strycula, "Active ac power filters," in Proc. IEEE IAS Meeting, 1976, pp. $529-535$.

[9] H.Akagi "A medium voltage transformerless AC/DC Power Conversion System Consisting of a Diode Rectifier and a Shunt Hybrid Filter" IAS Annual meeting,Vol.1,pp78;85,Oct.2002

[10] Bhim Singh,Vishal Verma,"An indirect current control ofhybrid power filters for varying loads",IEEE Transactions on power delivery vol. 21 no. 1 Jan 2006

[11] S. Bhattacharya, D. Divan and B. Banerjee, "Synchronous frame harmonic isolator using active series filter," EPE-Firenze, Vol. 3, pp. 30-35, 1991.

[12] P. Kirawanich and R. M. O'Connell, "Fuzzy Logic Control of an Active Power Line Conditioner," IEEE Trans-actions on Power Electronics, Vol. 19, No. 6, November 2004, pp. 1574-1585. doi:10.1109/TPEL.2004.836631

[13] E.E.EL-Khoy, A. EL-Sabbe, A.El-Hefnawy, and Hamdy M.Mharous, Three phase active power filter based on current controlled voltage source inverter, Electrical Power and Energy Systems,28(2006), 537-547.

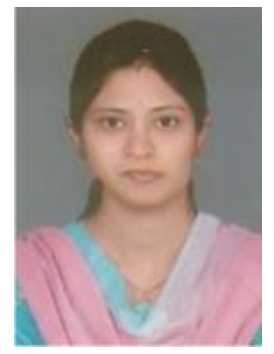

Sakshi Bangia received the B.Tech degree in Instrumentation and Control from MDU Rohtak and M.Tech degree in Electrical Engg. from YMCA UST in 2004 and 2006, respectively. She is pursuing Ph.D in Power Quality from Maharishi Dayanand University, India. Presently she is working as Assistant Professor in Electrical Engineering Department at YMCA UST Faridabad.

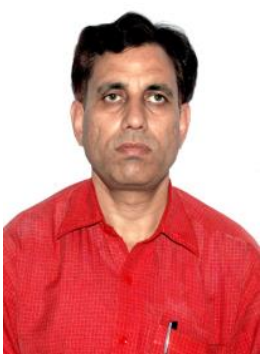

Dr. P.R.Sharma was born in 1966 in India. He is currently working as Head of the Department in Electrical Engg. in YMCA University of Science and Technology, Faridabad. He received his B.E Electrical Engineering in 1988 from Punjab University Chandigarh, M.Tech in Electrical Engineering (Power System) from Regional Engineering College Kurukshetra in 1990 and Ph.D from M.D.University Rohtak in 2005. He started his carrier from industry. He has vast experience in the industry and teaching. His area of interest is Optimal location and coordinated control of FACTS devices ,power system stability and control 




Dr. Maneesha Garg did her Ph.D(Physics) in 2002 from Kurukshetra University, India. After that she worked as Research Associate granted by CSIR, in NIT Kuru kshetra for 4 years. She has 18 publications in national, international journals and more than 30 papers in conferences to her credit. Presently she is working as Assistant Professor in Humanities and Applied Science Department, YMCA UST, Faridabad and guiding 4 scholars for their research work.

How to cite this paper: Sakshi Bangia, P R Sharma, Maneesha Garg,"Simulation of Fuzzy Logic Based Shunt Hybrid Active Filter for Power Quality Improvement", International Journal of Intelligent Systems and Applications(IJISA), vol.5, no.2, pp.96-104, 2013.DOI: 10.5815/ijisa.2013.02.12 